\title{
Effects of a Physical Exercise Program on the Level of Physical Activity and Energy Expenditure of Obese Workers in Kinshasa in the Democratic Republic of Congo
}

\author{
Godefroid K. Mabele ${ }^{1 *}$, Constant N. Ekisawa ${ }^{1}$, Christophe DELECLUSE ${ }^{2}$, Teddy B.Linkoko ${ }^{1}$, Nicaise K. Ngasa ${ }^{1}$, Francois L. Bompeka ${ }^{3}$ \\ ${ }^{I}$ Department of Physical Medicine and Rehabilitation, University of Kinshasa Faculty of Medicine, Democratic Republic of Congo \\ (DRC) Kinesiology service, \\ ${ }^{2}$ Faculty of movement and Rehabilitation sciences Departement of movement science K.U. Leuven, Belgique, \\ ${ }^{3}$ Department of Internal Medicine, University of Kinshasa Faculty of Medicine, Democratic Republic of Congo (DRC) Nephrology service
}

Corresponding Author: Godefroid K. Mabele, E-mail : kuswayi.mabele@unikin.ac.cd

\section{ARTICLE INFO}

Article history

Received: January 8, 2018

Accepted: March 26, 2018

Published: April 30, 2018

Volume: 6 Issue: 2

Conflicts of interest: None

Funding: None

\begin{abstract}
Background: Obesity has become a public health problem in the world today, especially in the workplace, where workers are subjected to long-term work in a sitting position and in front of computers. The absence of a program of structured physical exercises in our context on obesity in a professional environment in Kinshasa motivated us to carry out this study. Objective: To investigate the effect of a structured exercise program on the level of physical activity and energy expenditure of obese workers. Methods: In a 6-month follow-up study, 157 obese patients with a mean age of $47 \pm 9.54$ years were enrolled in a 3-day, one-hour structured exercise program. Day of moderate to high intensity and walking combined with a nutritional education (low calorie, high fiber and vitamins) at the Multimodal Freight Management Office of Kinshasa between January and June 2014. We used the paired Student's T test to compare continuous variables before and after the programs. Results: A significant increase was obtained in six months of the structured exercise program combined with nutrition education for most of the studied parameters: number of steps on the working day $(p<0.0001)$; number of steps on the weekend $(p<0.0001)$; energy expenditure on the working day $(p<0.0001)$; energy expenditure on the weekend day $(\mathrm{p}<0.0001)$. In contrast, weight, Body Mass Index, Waist circumference and Hip Abdomen Ratio significantly decrease d respectively: weight $(p<0.0001)$; Body Mass Index $(p<0.0001)$; waist circumference $(p<0.0001)$; Hip Abdomen Ratio $(p<0.0001)$.Conclusion: Structured exercise combined with nutrition education significantly increases the level of physical activity, energy expenditure and decreases weight, Body Mass Index, waist circumference and morbidity and mortality risk of obese workers.
\end{abstract}

Key words: Energy Expenditure, Structured Exercises, Obese

\section{INTRODUCTION}

Obesity is a dominant current issue. It is considered a major public health problem. Its management is a primary objective, given the growth of this disease and the consequences it has on health, justifying the improvement of therapeutic strategies including the methods of exercise (Karmisholt et al., 2005; Brooke et al.,2014). The level of physical activity of people in developed countries has steadily declined in recent decades to the point that physical inactivity has become a health risk factor along with smoking, and is one of the most important public health concerns (Kesaniemi et al., 2001; Vuori, 2001).It is now recognized that most of the chronic diseases that afflict our society are fundamentally linked to lifestyle (Chakravarthy et al., 2002) and whose sedentary lifestyle is one of the primary risk factors. The decrease in level of physical activity is therefore responsible for a biological imbalance directed by the hypothalamus, which would lead the person to a situation at risk of obesity (Rowland 1998).For the workers, it is rather the psychosocial and environmental aspects, such as the high grade and function, the level of training, and the accessibility of activities, which determine the decline in the level of physical activity (Dishman et al., 1985). In any case, a more restricted life, partitioned into offices, workshops, industries and mines, promotes lifestyles that are detrimental to health. Every living being subject to the laws of thermodynamics, it responds to the principle of conservation of energy. The body can be considered as a black box and any variation in mass can be explained by the difference between the outputs (total energy 
expenditure) and the inputs (energy ingested). It is the concept of energy balance according to which any gain in mass can result only from an increase of the caloric contributions and/or a reduction of the total energy expenditure (Bouchard et al., 2005; Serrano et al., 2016). On the other hand, all epidemiological, prospective and longitudinal studies have shown the key role of physical activity in preventing weight gain (Schmitz et al., 2000; Welk et al. 2011). Studies show that active subjects are less likely to gain weight over time than sedentary subjects are. Energy expenditure related to physical exercise can indeed be broken down into structured and spontaneous exercise (Morio et al., 1998). The interrelationships between these components of physical activity are complex and it has been shown that any intervention to improve exercise capacity through participation in a training program results in a parallel reduction of spontaneous exercise. The total energy spent on physical activity is very little changed by the intervention (Schrauwen et al., 1998; David et al., 2016). The importance of spontaneous exercise in weight control has recently been highlighted through the development of complex accelerometers and pedometers able to quantify it. Inter-individual variability in weight gain in response to over nutrition is shown to be related to the modulation of spontaneous exercise (Do Lee et al., 1999). In 2000 , the number of deaths related to unhealthy diet and inactivity were increased by $25 \%$ compared to the 1990 estimates (Mokdad et al., 2004). The data on inactivity is impressive. From 1950 to 2000, the time spent by day in front of the television almost doubled to reach about 8 hours a day at the beginning of the century. In recent years, there has been a march towards walking, which appears to be an activity with many health benefits in the world (Brownson et al., 2005).However, to our knowledge, no research has verified the effects of a structured exercise program combined with nutrition education on the level of physical activity and energy expenditure specifically designed for obese workers. It is to fill a gap that the present work was undertaken to evaluate the effects of a structured exercise program on the level of physical activity and energy expenditure of obese workers in a city Kinshasa province in the Democratic Republic of Congo.

\section{METHODS}

\section{Design of Study and Publication}

This is an experimental longitudinal study of 157 randomly selected obese workers from the staff list, including 76 men $(48.4 \%)$ and 81 women (51.6\%), of average age $47 \pm$ 9.54 years old, with a body mass index (BMI) greater than or equal to $30 \mathrm{Kg} / \mathrm{m} 2$, submitted during 6 months of combined physical exercise, between January and June 2014, held in a company in the provincial city Kinshasa in the Democratic Republic of Congo, known as the Office of Multimodal Freight Management, specializes in the multimodal transport sector, through appropriate regulatory mechanisms or specific actions, with a constant focus on research efficiency and profitability of any freight operation, from the producer to the consumer. His choice was justified in particular by the rela- tively better purchasing power of the workers who is characterized by the means of motorized travel and a social life without much trouble. As for the working conditions, they are too intense because most of his workers spend more than 7 hours of time sitting in front of the computer, on workdays and in front of Television, on weekends. All participants had given their informed written consent according to the Helsinki Declarations. They were all obese, aged 25 and over, and had been working regularly in one of the company's management for at least a year. The primary outcome measure being weight loss, all of these obese workers were assessed before (T0) and after 6 months of exercise programs (T6).

\section{Exercise Protocol}

We used a structured exercise protocol, combined with spontaneous, high-volume, moderate-to-high-intensity physical exercise at 3 sessions per week of one hour per day. This same program has also been associated with nutrition education. In this study, structured physical exercise includes voluntary physical exercise and supervised by professionals while spontaneous exercise includes all the actions of daily life. The prescribed physical exercises consisted of exercises in aerobic endurance including: jogging, rhythmic gymnastics, basketball, volley ball, swimming, walk of 10.000 not at the rate of three working days and two days of weekend recorded using a pedometer and muscle building exercises: thigh- abdominals-buttocks. These were combined with the spontaneous physical exercises below: walk, climb and go down the stairs instead of taking the elevator, go to the toilet on the upper floor than in his own hall, stretching.). This same program has also been associated with a nutritional education (low calorie, high in fiber and vitamins).

\section{Outcome Measure}

The following anthropometric parameters: height in centimeter was measured using the Seca brand portable toe, while waist circumference and hip circumference in a metric rate, the risk morbid-mortal by ratio Abdo-hip, the weight in kilograms by the Omron inpedancemetre BF -511 . Overall obesity among workers was defined by BMI $\geq 30 \mathrm{~kg} / \mathrm{m}^{2}$ calculated by mass (expressed in kilograms) divided by squared person size (in meters) and obesity android or abdominal by the International Diabetes Federation (IDF) criterion measured by waist circumference taken midway between the last rib and the iliac crest defined by the WHO action level 1 thresholds: waist circumference $\geq$ to $94 \mathrm{~cm}$ in men and waist circumference at $\geq 80 \mathrm{~cm}$ in women (Alexander et al., 2003; Dekker et al., 2005). The circumferential circumference $\geq 0$, $90 \mathrm{~cm}$ for men and $\geq 0.85 \mathrm{~cm}$ for women (Expert Panel on Detection, 2001, Adams et al., 2009).

The level of physical activity is determined by the number of steps per day and weekend, corresponding to an energy expenditure in the case of an impulse measured by the following values: physical inactivity: less than equal to 4999 steps (less than 300 Kilocalorie) per day, Slightly Active: between 5000 and 7499 steps (300 Kilocalories) per day, Some Active: between 7500 and 9990 steps (300 Kilocal- 
Table 1. Number of steps and energy expenditure before the exercise programs structured according to socio-professional status

\begin{tabular}{|c|c|c|c|c|}
\hline & $\begin{array}{l}\text { Command frameworks } \\
\qquad(\mathrm{N}=75)\end{array}$ & $\begin{array}{c}\text { Collaborative } \\
\text { frameworks }(\mathrm{N}=52)\end{array}$ & $\begin{array}{l}\text { Agents execution } \\
\qquad(\mathbf{N}=\mathbf{3 0})\end{array}$ & $\begin{array}{c}\text { Total } \\
(\mathbf{N}=157)\end{array}$ \\
\hline Age (year) & $49 \pm 10,61$ & $47 \pm 9,89$ & $45 \pm 6,72$ & $47 \pm 9,54$ \\
\hline $\begin{array}{l}\text { Number of steps per day } \\
\text { open }\end{array}$ & $1678 \pm 1458$ & $2764 \pm 1815$ & $3604 \pm 1836$ & $2682 \pm 1703,0$ \\
\hline $\begin{array}{l}\text { Number of steps per day of } \\
\text { week-end }\end{array}$ & $1456 \pm 1934,6$ & $1603 \pm 1050,5$ & $2365 \pm 1984,1$ & $1808 \pm 1956,4$ \\
\hline From the next day (Kcal) & $123 \pm 40,85$ & $172 \pm 68,87$ & $191 \pm 89,3$ & $162 \pm 66,34$ \\
\hline $\begin{array}{l}\text { From the days } \\
\text { week-end (Kcal) }\end{array}$ & $186 \pm 99$ & $234 \pm 96,85$ & $288 \pm 99,76$ & $236 \pm 98,54$ \\
\hline Weight (Kg) & $95 \pm 17,5$ & $92 \pm 14$ & $84 \pm 7,98$ & $90,4 \pm 13,16$ \\
\hline Size $(\mathrm{cm})$ & $170 \pm 7,86$ & $171 \pm 8,02$ & $168 \pm 7,97$ & $170 \pm 7,95$ \\
\hline Body mass index $\left(\mathrm{Kg} / \mathrm{m}^{2}\right)$ & $33,9 \pm 5,67$ & $31,7 \pm 4,52$ & $30 \pm 3,55$ & $32 \pm 4,58$ \\
\hline Waist circumference $(\mathrm{cm})$ & $106 \pm 84,21$ & $104 \pm 82,40$ & $99 \pm 80,77$ & $103 \pm 82,46$ \\
\hline Hip circumference (cm) & $112 \pm 8,06$ & $114 \pm 11,98$ & $113 \pm 10,2$ & $113 \pm 10,08$ \\
\hline Hip abdomen ratio & $0,94 \pm 6,5$ & $0,91 \pm 5,87$ & $0,87 \pm 5,03$ & $0,90 \pm 5,80$ \\
\hline
\end{tabular}

Table 2. Number of steps and energy expenditure after exercise programs structured according to socio-professional status

\begin{tabular}{|c|c|c|c|c|}
\hline & $\begin{array}{c}\text { Command frameworks } \\
(\mathrm{N}=75)\end{array}$ & $\begin{array}{l}\text { collaborative frameworks } \\
\qquad(\mathrm{N}=52)\end{array}$ & $\begin{array}{c}\text { Agents execution } \\
(\mathbf{N}=\mathbf{3 0})\end{array}$ & $\begin{array}{c}\text { Total } \\
(\mathrm{N}=157)\end{array}$ \\
\hline Age (year) & $49 \pm 10,61$ & $47 \pm 9,89$ & $45 \pm 6,72$ & $47 \pm 9,54$ \\
\hline $\begin{array}{l}\text { Number of steps per day } \\
\text { open }\end{array}$ & $11264 \pm 2192,8$ & $11350 \pm 2591$ & $11424 \pm 2546,7$ & $11346 \pm 2443,5$ \\
\hline $\begin{array}{l}\text { Number of steps per day of } \\
\text { week-end }\end{array}$ & $11229 \pm 2031,7$ & $11991 \pm 2731$ & $12138 \pm 2876,2$ & $11789 \pm 2546,3$ \\
\hline From the next day (Kcals) & $1748 \pm 380,8$ & $1736 \pm 399,4$ & $1954 \pm 491,2$ & $1812 \pm 423,8$ \\
\hline $\begin{array}{l}\text { From the days } \\
\text { week-end (Kcals) }\end{array}$ & $1786 \pm 1893,6$ & $1879 \pm 2031,2$ & $1982 \pm 2176$ & $1881 \pm 2033,6$ \\
\hline Weight (Kg) & $85 \pm 8,87$ & $75 \pm 8,09$ & $59,5 \pm 7,97$ & $70,5 \pm 8,31$ \\
\hline Size $(\mathrm{cm})$ & $170 \pm 7,86$ & $171 \pm 8,02$ & $168 \pm 7,97$ & $170 \pm 7,95$ \\
\hline Body mass index $\left(\mathrm{Kg} / \mathrm{m}^{2}\right)$ & $30,7 \pm 2,79$ & $26,5 \pm 2,03$ & $21,6 \pm 2,02$ & $26,2 \pm 2,28$ \\
\hline Waist circumference $(\mathrm{cm})$ & $89 \pm 5,68$ & $85 \pm 5,03$ & $72 \pm 4,05$ & $82 \pm 4,92$ \\
\hline Hip circumference $(\mathrm{cm})$ & $109 \pm 8,67$ & $110 \pm 10,05$ & $111 \pm 11,1$ & $110 \pm 10,09$ \\
\hline Hip Abdomen Ratio & $0,82 \pm 9,05$ & $0,77 \pm 6,99$ & $0,65 \pm 4,87$ & $0,74 \pm 6,97$ \\
\hline
\end{tabular}

ories) per day, Active:> 10000 (greater than or equal to 300 Kilocalories) and Highly Active:> 12000 steps (greater than or equal to 300 Kilocalories) per day (Tudor-Locke et al., 2008a; Tudor-Locke et al., 2000b).

\section{Statistical Analysis}

After the quality check for missing or aberrant data, the collected data was captured on a PC, with the EPI INFO software and analyzed using the SPSS 21.0 software. Quantitative variables were expressed as means \pm standard deviation. The comparison of the averages of the continuous variables (T0 versus T6) was performed by the paired Student t-test. A value of $\mathrm{p} \leq 0.05$ was considered a threshold of statistical significant.

\section{RESULTS}

Table 1 Prior to the structured exercise program, the subject parameters were: number of steps per working day $2682 \pm$ 1703.0, number of steps per weekend day $1808 \pm 1956.4$, energy expenditure on working days $162 \pm 66,34$ Kcals, energy expenditure on weekend days $236 \pm 98.54$ Kcals, weight $90.4 \pm 13 \mathrm{~kg}$, Body Mass Index $32 \pm 4.58 \mathrm{Kg} / \mathrm{m}^{2}$, Waist circumference $103 \pm 82.46 \mathrm{~cm}$, Hip circumference $113 \pm 10.08 \mathrm{~cm}$, hip abdomen ratio $0.90 \pm 5.80 \mathrm{~cm}$.

After a follow-up of six months of management combined with a nutritional education, the corresponding levels of physical activity and energy activity are as follows in Table 2: number of steps per working day $11346 \pm 2443.5$, number of steps per day of week -end $11789 \pm 2546.3$, en- 
Table 3. Comparison of step, energy and anthropometric expenditure parameters before and after the structured exercise program combined with nutrition education

\begin{tabular}{lccc}
\hline & Before $(\mathbf{n}=\mathbf{1 5 7})$ & After $(\mathbf{n}=\mathbf{1 5 7})$ & p-value \\
\hline Number of steps per day open & $2682 \pm 703,0$ & $11346 \pm 2443,5$ & $<0,0001$ \\
Number of steps per day of week-end & $1808 \pm 1956,4$ & $11789 \pm 2546,3$ & $<0,0001$ \\
From the next day (Kcal) & $162 \pm 66,34$ & $1812 \pm 423,8$ & $<0,0001$ \\
From the days week-end (Kcal) & $236 \pm 98,54$ & $1881 \pm 2033,6$ & $<0,0001$ \\
Weight $(\mathrm{Kg})$ & $90,4 \pm 13,16$ & $70,5 \pm 8,31$ & $<0,0001$ \\
Body mass index $\left(\mathrm{Kg} / \mathrm{m}^{2}\right)$ & $32 \pm 4,58$ & $26,2 \pm 2,28$ & $<0,0001$ \\
Waist circumference $(\mathrm{cm})$ & $90,4 \pm 13,16$ & $70,5 \pm 8,31$ & $<0,0001$ \\
Hip circumference $(\mathrm{cm})$ & $103 \pm 82,46$ & $82 \pm 4,92$ & $<0,0001$ \\
Hip abdomen ratio & $0,90 \pm 5,80$ & $0,74 \pm 6,97$ & $<0,0001$ \\
\hline
\end{tabular}

ergy expenditure on working days $1812 \pm 423.8$ Kcal, energy expenditure on week-end days $1881 \pm 2033.6 \mathrm{Kcal}$, weight $74.5 \pm 8.31 \mathrm{Kg}$, Body Mass Index $26.2 \pm 2.28 \mathrm{Kg} / \mathrm{m}^{2}$, Waist circumference $82 \pm 4.92 \mathrm{~cm}$, Hip circumference $110 \pm$ $10.09 \mathrm{~cm}$, Hip Abdomen Ratio $0.74 \pm 6.97 \mathrm{~cm}$.

This Table 3 has shown that a significant increase in the level of physical activity and energy expenditure was observed on weekdays and weekends. The anthropometric parameters were significantly reduced in six months of structured exercises combined with a nutritional education.

\section{DISCUSSION}

The present study has shown the effects in six months of a structured exercise program combined with nutrition education on the level of physical activity, energy expenditure and anthropometric parameters of a cohort of 157 obese workers, including 81 women. (51.6\%) and 76 men (48.4\%).In six months of structured exercises combined with nutritional education, a significant increase was obtained for most of the parameters studied: number of steps on the working day (+8664); number of steps on the day weekend (+ 9981pas); energy expenditure on the working day $(+1650 \mathrm{Kcals})$; energy expenditure on the weekend $(+1645 \mathrm{Kcals})$. On the other hand, weight, Body Mass Index, Waist circumference and Hip Abdomen Ratio significantly decreased respectively: weight $(-19.9 \mathrm{Kg})$; Body Mass Index $\left(-5.8 \mathrm{Kg} / \mathrm{m}^{2}\right)$; waist circumference $(-20.1 \mathrm{~cm})$; Hip Abdomen Ratio $(-0.16 \mathrm{~cm})$. High socioeconomic status, advancement in age, and sedentary lifestyle expose obese employees to cardiovascular and metabolic complications such as high blood pressure, diabetes, stroke, and kidney disease. In this regard, studies have indicated that the increase in the level of physical activity and the decrease in sedentary lifestyles have positive effects on obesity (Ortega et al., 2005).In the presence of obesity, it is recommended to increase the volume of physical activity needed more than the recommended volume for normal weight workers. The practice of walking a good 180 minutes a week would have a positive and protective effect on weight gain and its metabolic consequences (Ortega et al., 2005). In addition, the use of structured exercises combined with nutrition education, increases the level of physical activity and decreases the level of inactivity alone, makes it difficult to reach a negative energy balance that would favor the de- crease of anthropometric parameters. (Tjonna et al., 2008). Other guidelines are focused more specifically on the maintenance of morphology, in particular that of Tudor-Locke, which recommends that obese persons perform between 7,000 to 10,000 steps per day, 8,000 of which are performed during moderate intensity activity or high (Kim et al. 2009; katzmarzy et al. 2009). Researchers recommend that, in order to manage obesity, encourage activities of a continuous or intermittent aerobic nature and of medium to high intensity (Jago et al., 2006). Adams has suggested that regular physical activity allows for the long-term maintenance and weight loss of an obese person. The promotion of daily physical activity is also encouraged through games, sports, the use of active travel (walking, cycling), active recreation and family exercise (Tudor-Locke.et al., 2008a). Indeed, the new guidelines recommend the practice of a minimum of $60 \mathrm{~min}$ utes of moderate to high physical activity per day in addition to physical activities related to daily living In addition, it is recommended to engage in a variety of intensity activities daily, including a minimum of 3 high intensity aerobic sessions and maximize duration to achieve a high volume of weekly physical activity. Activities should include high intensity activities at least 3 days a week and muscle building activities at least 3 days a week (Kino-Québec., 2011; Adams et al., 2009).In obese patients, the use of vigorous physical activity rather than caloric restriction in order to reduce anthropometric parameters seems to be recommended by the literature (Eisenmann et al., 2005; Eliakim et al., 2000). However, in other studies, the decrease in anthropometric parameters was unsuccessful following a treatment that targeted physical activity. These data suggested that physical activity alone is not the best way to reduce the anthropometric parameters of the obese, despite its benefits for different risk factors (Stallmann-Jorgensen et al., 2007) At the global level, WHO has recommended the promotion of health programs through the practice of physical activity in a variety of settings (Gutin et al., 2002). In this sense, it is emphasized that in the area of prevention, businesses represent environments conducive to physical activity initiatives and support for a physically active lifestyle. Several researchers have shown that the combined practice of regular physical activity significantly reduces abdominal obesity and morbidity-mortality risks (Tjonna et al., 2009; brooke et al.,2014). At present, there was little scientific evidence for an appre- 
ciable effect of physical exercise on body weight reduction. The challenge was therefore to combine a nutritional education and a structured physical activity supervised by professionals (Atlantis et al., 2006). The major limitation of our study is simple random sampling as the socio-professional status effect where the cadres constituted the majority of subjects studied compared to the executing agents. A major strength of this study lies in the fact that it represents the first longitudinal interventional study in the workplace in Kinshasa where it has implemented a combined physical activity program and sought on the one hand, the effect non-pharmacological measures on the level of physical activity and, on the other hand, on energy expenditure among obese employees. Future research is encouraged to investigate the effect of this structured and spontaneous exercise program on body composition, muscle strength, cardiac fitness, and cardiovascular risk factors related to the metabolic syndrome in obese workers from Kinshasa.

\section{CONCLUSION}

The structured exercise program combined with a nutrition education (low calorie, high in fiber and vitamins) and associated with active lifestyle exercises every two hours; significantly increases the level of physical activity, energy expenditure and improves weight, waist circumference, morbi-mortal risks related to the sedentariness of obese Kinshasa workers. It can be considered as an effective non-pharmacological strategy for treating the risk generated by obesity.

\section{REFERENCES}

Adams, J. B., Edwards, D., Serviette, D., Bedient, A. M., Huntsman, E., Jacobs, K. A., \& Signorile, J. F. (2009). Optimal frequency, displacement, duration, and recovery patterns to maximize power output following acute whole-body vibration. The Journal of Strength \& Conditioning Research, 23(1), 237-245. doi: 10.1519/ JSC.0b013e3181876830.

Atlantis E, Barnes EH and Singh MAF. (2006). Efficacy of exercise for treating overweight in children and adolescents: a systematic review. International Journal of Obesity, 30(7), 1027-1040.

Bouchard, C. (2005). Aerobic fitness, body mass index, and CVD risk factors among adolescents: the Quebec family study. International Journal of Obesity, 29(9), 1077-1083.

Brooke E. Starkoff, Inhuman U. Eneli, Andrea E. Bonny, Robert P. Hoffman Steven T. Devor. (2014). Estimated Aerobic Capacity Changes in Adolescents with Obesity Following High Intensity Interval Exercise. International Journal of Kinesiology \& Sports Science, 2(3), 1-8.

Brownson R. C., Boehmer T. K. \& Luke D.A. (2005). Declining rates of physical activity in the United States: what are the contributors? Annual Revue Public Health, 26, 421-443.

Chakravarthy MV, Joyner MJ, and Booth FW (2002).An obligation for primary care physicians to prescribe physical activity to sedentary patients to reduce the risk of chronic health conditions. Mayo Clinic Processes, 77, 165-173.
David C. Archer, Lee E. Brown, Jared W. Coburn, Andrew J. Galpin, Phillip C. Drouet, Whitney D. Leyva, Cameron N. Munger, Megan A. Wong. (2016). Effects of Short-Term Jump Squat Training With and Without Chains on Strength and Power in Recreational Lifters. International Journal of Kinesiology \& Sports Science, 4(4), 24-31.

Dekker, J.M. (2005). Metabolic syndrome and 10-year cardiovascular disease risk in the Hoorn Study. Circulation, $112,666-673$

Dishman RK, Sallis JF, and Orenstein DR. (1985).The determinants of physical activity and exercise. Public Health Republic, 100, 158-171.

Do Lee, C., Blair, S. N., \& Jackson, A. S. (1999). Cardio respiratory fitness, body composition, and all-cause and cardiovascular disease mortality in men. The American journal of clinical nutrition, 69(3), 373-380.

Dwyer, T., Magnussen, C. G., Schmidt, M. D., Ukoumunne, O. C., Ponsonby, A.-L., Raitakari, O. T., Cleland, V. J. (2009). Decline in physical fitness from childhood to adulthood associated with increased obesity and insulin resistance in adults. Diabetes Care, 32(4), 683-687.

Eisenmann, J. C., Katzmarzyk, P., Perusse, L., Tremblay, A., Despres, J., \& Bouchard, C. (2005). Aerobic fitness, body mass index, and CVD risk factors among adolescents: the Quebec family study. International Journal of Obesity, 29(9), 1077-1083.

Eliakim A, Makowski GS, Brasel JA and Cooper DM. (2000). Adiposity, lipid levels, and brief endurance training in non-obese adolescent males. International Journal of Sports Medicine, 21(6), 332-337.

Expert Panel on Detection E. (2001).Treatment of High Blood Cholesterol in A. Executive Summary of The Third Report of The National Cholesterol Education Program (NCEP) Expert Panel on Detection, Evaluation, And Treatment of High Blood Cholesterol In Adults (Adult Treatment Panel III). JAMA: The Journal of the American Medical Association, 285(23), 2486-97.

Gutin, B., Barbeau, P., Owens, S., Lemmon, C. R., Bauman, M., Allison, J., Litaker, M. S. (2002). Effects of exercise intensity on cardiovascular fitness, total body composition, and visceral adiposity of obese adolescents. The American journal of clinical nutrition, 75(5), 818-826.

Jago R, Watson K, Baranowski T, Zakeri I, Yoo S, Baranowski J and Conry K. (2006). Pedometer reliability, validity and daily activity targets among 10- to 15-year-old boys. Journal of Sports Sciences, 24(5), 241-251.

Karmisholt K, Gyntelberg F, and Gotzche PC. (2005). Physical activity for primary prevention of disease. Systematic reviews of randomized clinical trials, 52, 86-89.

Katzmarzyk, P. T., Church, T. S., Janssen, I., Ross, R., \& Blair, S. N. (2005). Metabolic Syndrome, Obesity, and Mortality Impact of cardiorespiratory fitness. Diabetes Care, 28(2), 391-397.

Kesaniemi YA, Danforth E, Jensen MD, Kopelman PG, Lefebvre P, and Reeder BA. (2001). Dose-response issues concerning physical activity and health: an evidence-based symposium. Medicine Science Sports Exercise,4(4), S351-S358. 
Kim Y and Lee S. (2009). Physical activity and abdominal obesity in youth. Applied Physiology, Nutrition, And Metabolism, Physiologie Appliquée, Nutrition et Métabolisme, 34, 571-581.

Kino-Québec Csd. (2011). L'activité physique, le sport et les jeunes - Savoir et agir. Québec: Secrétariat au loisir et au sport, ministère de l'Éducation, du Loisir et du Sport. Gouvernement du Québec.

Mokdad A. H., Marks J. S., Stroup D. F., Gerberding J. L. (2004). Actual causes of death in the United States, 2000. The Journal of the American Medical Association, 291(23), 1238-1245.

Morio B., Montaurier C., Pickering G., Ritz P., Fellmann N., Coudert J., Beaufrere B. \&Vermorel M. (1998). Effects of 14 weeks of progressive endurance training on energy expenditure in elderly people. British Journal of Nutrition, 80, 511-519.

Ortega, F. B., Ruiz, J. R., Castillo, M. J., Moreno, L. A., González-Gross, M., Wärnberg, J., \& Gutiérrez, Á. (2005). Low level of physical fitness in Spanish adolescents. Relevance for future cardiovascular health (AVENA study). Revista Española de Cardiología (English Edition), 58(8), 898-909.

Rowland TW. (1998). The biological basis of physical activity. Medicine Science Sports Exercise, 30(5), 392-399.

Schmitz K. H., Jacobs D. R. Jr., Leon A. S., Schreiner P. J., Sternfeld B. (2000). Physical activity and body weight: associations over ten years in the CARDIA study. Coronary Artery Risk Development in Young Adults. International Journal of Obesity, 4(9), 1475-1487.

Schrauwen P., Lichtenbelt W. D., Saris W. H. \&Westerterp K. R. (1998). Fat balance in obese subjects: role of glycogen stores. American Journal of Physiology, 74, E1027-E1033.

Serrano-Huete, V., Latorre-Román, P. A., García-Pinillos, F., MorcilloLosa, J. A., Moreno-Del Castillo, R., \&Párra-
ga-Montilla, J. A. (2016). Acute effect of a judo contest on muscular performance parameters and physiological response. International Journal of Kinesiology \& Sports Science, 4(3), 24-31.

Stallmann-Jorgensen IS, Gutin B, Hatfield-Laube JL, Humphries MC, Johnson MH and Barbeau P. (2007). General and visceral adiposity in black and white adolescents and their relation with reported physical activity and diet. International Journal of Obesity, 31(7), 622-629.

Tjonna, A. E., Lee, S. J., Rognmo, O., Stolen, T. O., Bye, A., Haram, P. M., Wisloff, U. (2008). Aerobic interval training versus continuous moderate exercise as a treatment for the metabolic syndrome: a pilot study. Circulation, 118(4), 346-354. doi: 10.1161/CIRCULATION AHA. 108.772822

Tjonna, A. E., Stolen, T. O., Bye, A., Volden, M., Slordahl, S. A., Odegard, R., Wisloff, U. (2009). Aerobic interval training reduces cardiovascular risk factors more than a multitreatment approach in overweight adolescents. Clinical Science, 116(4), 317-326. doi: 10.1042/CS20080249.

Tudor-Locke C, Hatano Y, Pangrazi RP and Kang M. (2008a). Revisiting "how many steps are enough. Medicine and Science in Sports and Exercise, 40(4), S537-S543.

Tudor-Locke CE, Myers AM. (2000b). Methodological Considerations for Researchers and Practitioners using Pedometers to Measure Physical (Ambulatory) Activity. Research Questionnaire Exercise Sports, 2, 1-12.

Vuori IM. (2001). Dose-response of physical activity and low back pain, osteoarthritis, and osteoporosis. Medicine and Science in Sports and Exercise, 3(4), S551-586.

Welk, G. J., Laurson, K. R., Eisenmann, J. C., \& Cureton, K. J. (2011). Development of youth aerobic-capacity standards using receiver operating characteristic curves. American Journal of Preventive Medicine, 41(4 Suppl 2), S111-116. doi: 10.1016/j.amepre.2011.07.007 